\title{
Autoinjerto de tejido conectivo para aumento del volumen de tejidos blandos. Indicaciones y aplicación clínica
}

\author{
ESCUDERO-CASTAÑO N* \\ LORENZO-VIGNAU R* \\ PEREA-GARCÍA MA* \\ BASCONES-MARTÍNEZ A**
}

\begin{abstract}
Escudero-Castaño N, Lorenzo-Vignau R, Perea-García MA, BasconesMartínez A. Autoinjerto de tejido conectivo para aumento del volumen de tejidos blandos. Indicaciones y aplicación clínica. Av Periodon Implantol. 2008; 20, 2: 113-120.
\end{abstract}

\section{RESUMEN}

En general, la zona edéntula residual impide una correcta relación estéticaentre póntico y cresta, desencadenando una falta de estética en casos en los cuales queda implicado el frente anterior. Para corregir este tipo de defectos podremos utilizar distintas técnicas de aumento de tejido y con un correcto manejo del mismo con la ayuda de un póntico ovoide. El objetivo de este artículo es demostrar a través de un caso clínico una técnica de modificación tisular en una zona con defecto clase III de Seibert a través de un injerto de tejido conectivo y un póntico ovoide.

\section{PALABRAS CLAVE}

Clasificación de Seibert, injerto de tejido blando, Cantilever.

Fecha de recepción: Enero 2007.

Aceptado para publicación: Febrero 2007.

\section{INTRODUCCIÓN}

Existen determinadas zonas en la dentición comprometidas con el tratamiento restaurador en las que prevalece una demanda de encía queratinizada.

La presentación de un reborde alveolar parcialmente edéntulo puede llegar a conservar la forma de la apófisis alveolar, junto a sus dimensiones vestibulolinguales y apicocoronales, denominándose tradicionalmente reborde anormal. Actualmente, se ha comprobado que esta gran conservación no es lo que se produce habitualmente, debido a la alteración de tejidos duros y blandos circundantes, entre ellos, la pérdida de estructuras anatómicas como las eminencias óseas radiculares o las papilas interdentales, lo cual dificultaría la obtención de la futura estética tras restaurar la zona. Esta falta de estética se produciría por la existencia de triángulos negros entre pilar y póntico, o por la sensación de un apoyo del póntico de la fase restauradora sobre el reborde crestal en lugar de emerger desde el interior del reborde alveolar. 
El colapso de los tejidos duros y blandos puede ser consecuencia de extracciones dentales, enfermedad periodontal avanzada, formación de abscesos, traumatismos, etc. Para prevenir el colapso tras extracción, se plantean diversos procedimientos a realizar tales como la colocación inmediata de un póntico ovoide, abordaje con colgajo para la exodoncia, la colocación de un injerto de tejido blando y/o hueso, o implantes inmediatos.

Según Seibert (1), una vez producidos los defectos por el colapso del reborde alveolar, podrían clasificarse, en función de la pérdida de dimensión vestibulolingual o apicocoronaria:

- La clase I supondría una pérdida de la dimensión vestibulolingual, conservando una altura apicocoronaria.

- La clase II presentaría una pérdida de la altura apicocoronaria, preservando la dimensión vestibulolingual.

- En la clase III existe una pérdida de altura y espesor de la cresta.

En 1985 Allen (2) realiza una modificación de esta clasificación, denominando:

- Clase A a la pérdida de la dimensión apicocoronal.

- Clase B a la pérdida de la dimensión bucolingual.

- Clase $\mathrm{C}$ a la pérdida de la dimensión apicocoronal y bucolingual.

Allen también introduce el concepto de severidad, valorando los defectos de menos de $3 \mathrm{~mm}$ como leves, los de 3 a $6 \mathrm{~mm}$ como moderados y los mayores de 6 $\mathrm{mm}$ como graves.

Antes de proceder a cualquier tratamiento para corregir el defecto estético o de encía queratinizada creado por el colapso del reborde alveolar, hay que proceder a analizar el volumen tisular requerido para eliminar la deformidad del reborde alveolar, considerando los distintos tipos de procedimientos de injerto a realizar, establecer una sistemática en los procedimientos terapéuticos a realizar, planificar el diseño de la restauración provisional, prever los problemas potenciales por pigmentación o igualamiento del color de los tejidos.

A lo largo de los años se han descrito diversos procedimientos cuyo objetivo era la reconstrucción de un reborde parcialmente desdentado a través del aumento con tejidos duros o blandos.
Existen distintos tipos de injertos de tejido blando para el aumento de cresta. Se pueden clasificar en injertos pediculados y libres.

\section{Injertos pediculados}

Dentro de los tipos de injerto pediculado, podremos destacar el procedimiento de colgajo Rodado (3) que consiste en la preparación de un colgajo pediculado de tejido conectivo desepitelizado de forma rectangular por palatino del defecto, y con unas dimensiones equivalentes a la cantidad de prominencia radicular que presentan las raíces que limitan el defecto. El colgajo se despega, con especial precaución de no perforarlo durante su elevación. A continuación, creamos un "sobre" a nivel vestibular del tejido conectivo supraperióstico, lo más cerca posible del periostio, para facilitar la vascularización del injerto pediculado. Introducimos el pedículo, lo adaptamos en la posición deseada dentro del sobre y procedemos a la sutura en una posición apical para permitir un posicionamiento y estabilización del injerto apicalmente. Tras la sutura posicionamos cemento quirúrgico sobre la zona donante para que el postoperatorio de la paciente se desarrolle de una forma más indolora. Las indicaciones de este tipo de tratamiento son los defectos que comprenden la clase I de Seibert (1) de tamaño pequeño a moderado.

\section{Injertos libres}

Por otro lado, la otra clase de injertos de tejido blando para el aumento del reborde alveolar, serían los injertos libres de tipo insaculado o en túnel, interpuesto o inlay y superpuesto u onlay.

En los procedimientos de injerto en túnel $(2,4)$, se crea un sobre subepitelial en el área de la deformidad de la cresta. Esta preparación se podría desarrollar con tres técnicas de incisión diferentes; en primer lugar, la técnica que consiste en una incisión coronaria efectuada por palatino o lingual del defecto, denominada coronoapical; o una segunda técnica que consiste en una incisión horizontal cerca de la unión mucogingival por el área vestibular, denominándose apicocoronaria (2); o tercera técnica que se basa en una o dos incisiones verticales con gran bisel de carga lateral por alguno de los defectos del defecto (4). Acto seguido, se procede a la toma del injerto de tejido conectivo, los lugares donantes ideales son la tuberosidad, un área edéntula o el paladar. Existen diversas técnicas 
para la obtención del injerto, Langer y Langer, en 1985 describía la técnica trampilla basada en la realización de tres incisiones, dos verticales y una horizontal; Bruno en 1994, describía otra técnica que consistía en la realización de dos incisiones lineales horizontales; por último, Hurzeler descrita, en 1999, una técnica en la que realiza una única incisión lineal, situamos a continuación el injerto en la zona receptora y suturamos. En los defectos de clase I de Seibert el uso de esta técnica estaría indicada.

En las técnicas de injerto interpuesto o inlay (5) los injertos de tejido conectivo no están cubiertos de manera completa por tejido epitelial alrededor del defecto, existiendo cierta cantidad de conectivo expuesto a la cavidad bucal, por lo que no hace necesario desepitelizar toda la superficie de la zona donante.

En los procedimientos superpuestos u onlay (6), se prepara el lecho receptor desepitelizando el tejido epitelial, y superponiendo un injerto libre de tejido epitelizado para ganar altura del reborde alveolar; este tipo de injertos estarían indicados en la clase III de Seibert.

\section{Pónticos}

Tras la realización de la cirugía se procede al manejo de los tejidos blandos a través de pónticos, éstos pueden ser de tipo higiénico, en silla de montar, ovoide, etc. (7).

\section{Objetivos}

En el presente artículo aplicaremos un injerto interpuesto o inlay con un manejo de tejidos blandos a través de un póntico ovoide, desarrollado por Abrams en 1980 , creado para superar los inconvenientes de los pónticos tradicionales (7).

\section{PRESENTACIÓN DEL UN CASO CLÍNICO}

\section{DIAGNÓSTICO}

Presentamos una paciente de 41 años de edad, no fumadora, que no refiere ninguna enfermedad sistémica $\mathrm{y}$, actualmente, no esta siendo sometida a ninguna terapia farmacológica. El motivo por el cual acudió a la consulta odontológica fue la falta de estética alrededor de la zona edéntula del frente anterior. Según la clasifica- ción de House (8) en la que se describen la psicología y la actitud del paciente ante el profesional, correspondería con un paciente filosófico, receptivo, colaborador y con altas expectativas sobre sus tratamientos; dando preferencia, primero a su estética, segundo a la salud y por último a la función. Según la clasificación de la Sociedad Americana de Anestesiología era un paciente ASA tipo I, es decir, un paciente sano sin haber sido sometido a ninguna cirugía electiva. La atención odontológica recibida hasta el momento había sido regular, al haber acudido anualmente a su odontólogo.

Antes de cualquier tipo de intervención, el paciente firmó un consentimiento informado. Tras una correcta valoración de la historia clínica, se realizó una ortopantomografía y una serie periapical de la paciente, y se tomaron los diferentes registros clínicos como la profundidad de sondaje (PS), recesiones, presencia de lesiones de furca, grados de movilidad, índice de placa, sangrado al sondaje, etc. Nuestro paciente presentaba una higiene oral adecuada, donde los índices de placa y de cantidad de sangrado de Muhlemann y Son (9) estaban controlados, todos los dientes presentan vitalidad positiva y no existía presencia de caries. La paciente presentaba un implante straumann desde hace 6 años, y debido a problemas planificación la paciente continua con la prótesis provisional.

\section{DESARROLLO DE LA INTERVENCIÓN QUIRÚRGICA}

Al centrarnos en la estética del frente anterior, observamos que la paciente presenta un defecto clase III de Seibert (1) en la zona del póntico a nivel de la pieza 21 (Fig. 1), para proceder a la intervención extraemos el puente para acceder a la zona quirúrgica (Fig. 2). Realizamos una incisión a espesor parcial iniciada en el aspecto palatino de la cresta, dejando un lecho perióstico para la vascularización del injerto (Fig. 3), una vez reflejado ligeramente el tejido blando que cubre la cresta hacia vestibular, se continua profundizando dentro del espesor del colgajo a espesor parcial hasta sobrepasar la línea mucogingival a nivel apical y extendiéndonos lateralmente en la cara vestibular unos 3 ó 4 milímetros hacia los dientes vecinos (Fig. 4). Las características principales del lecho son su capacidad para formar capilares para la vascularización del colgajo y su adecuada hemostasia $(10,11)$, es decir, crear un acondicionamiento capaz de facilitar la adaptación del injerto y su futura viabilidad; finalmente obtenemos el avance coronario del colgajo mucoso en el momento de suturar. 


\section{AVANCES}

Volumen 20 - $\mathrm{N}^{\circ} 2$ - Agosto 2008

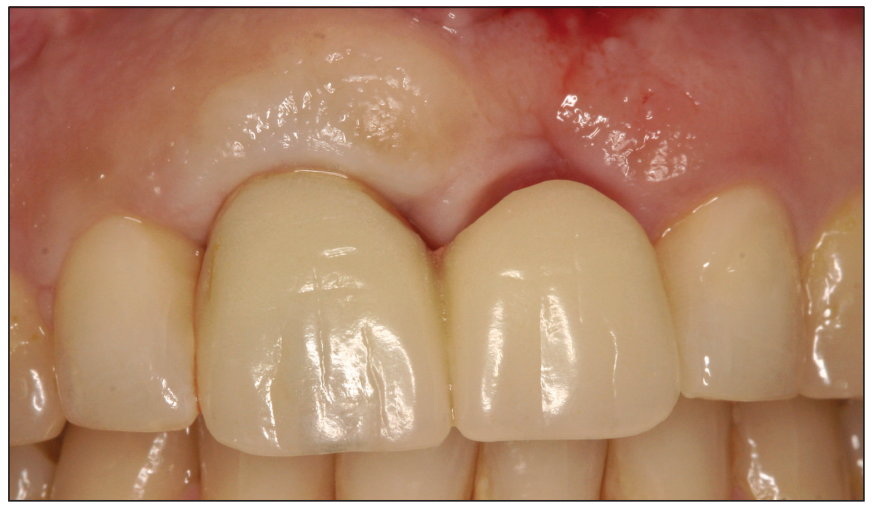

Fig.1: Zona prequirúrgica, clase III de Seibert.



Fig.2: Zona prequirúgica tras la extracción del póntico.

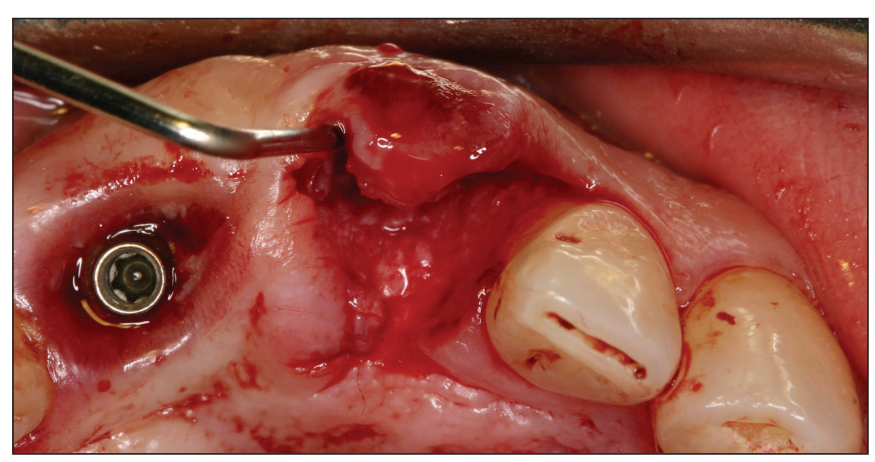

Fig.3: Preparación del lecho receptor desde el plano oclusal.

Se procede a la obtención del injerto de tejido conectivo de la zona donante palatina (Fig. 5) mediante la técnica descrita por Bruno. Suturamos la zona palatina con puntos simples y se realiza una ligera presión sobre la zona mediante gasas para facilitar la hemostasia (Fig. 6). Mientras procedemos a acondicionar la zona receptora, mantendremos el injerto en una gasa impregnada en suero salino (10).

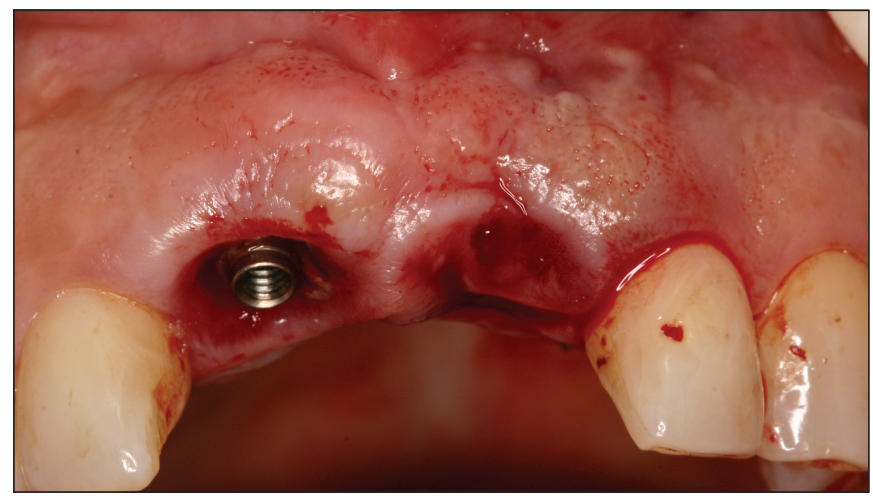

Fig.4: Preparación del lecho receptor desde vestibular.

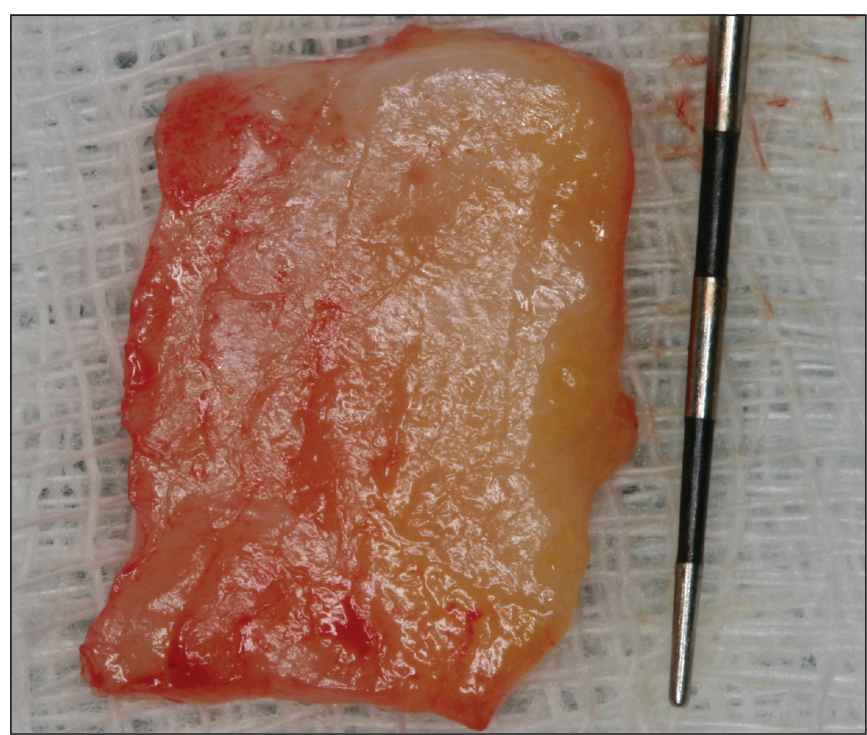

Fig.5: Injerto de tejido conectivo.

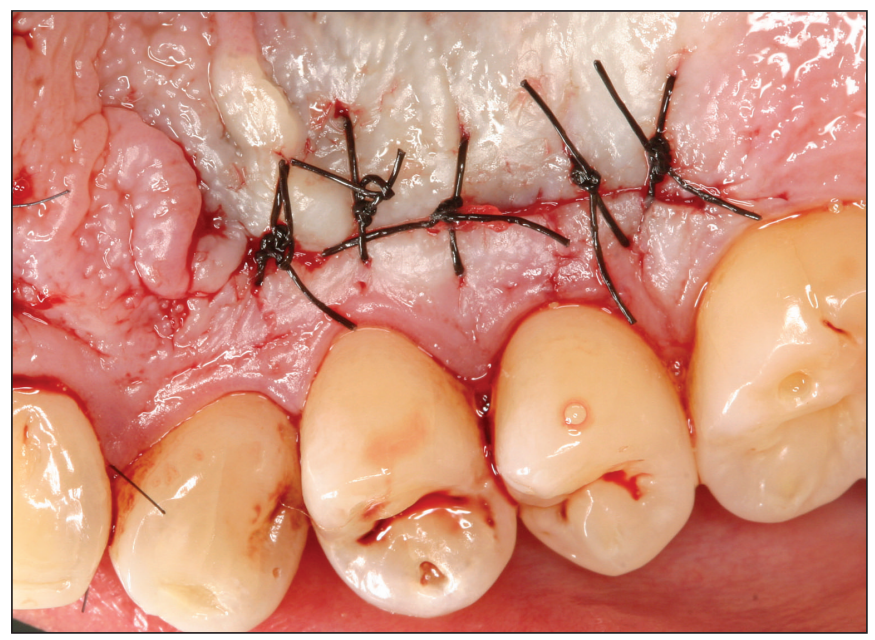

Fig.6: Sutura de la zona dadora. 
Para posicionar el injerto en zona receptora, a nivel de la línea mucogingival se introduce la aguja desde la mucosa, de tal forma que salga por la incisión crestal inicial; luego, se realiza un colchonero horizontal en un extremo del injerto y se vuelve a introducir a través del "sobre" creado para que la aguja salga a nivel de la sutura inicial. La inserción del injerto se realizará traccionando apicalmente de los extremos de la sutura que sobresalen por vestibular, y con la ayuda de la sonda u otro instrumento no cortante nos ayudamos a empujar el injerto dentro del lecho (Figs. 7 y 8). Una vez que el injerto ha llegado a la profundidad deseada (Fig. 9), dejando una parte del injerto de tejido conectivo sin cubrir, se anudan ambos extremos del hilo. Acto seguido, se sutura el injerto a la zona palatina y

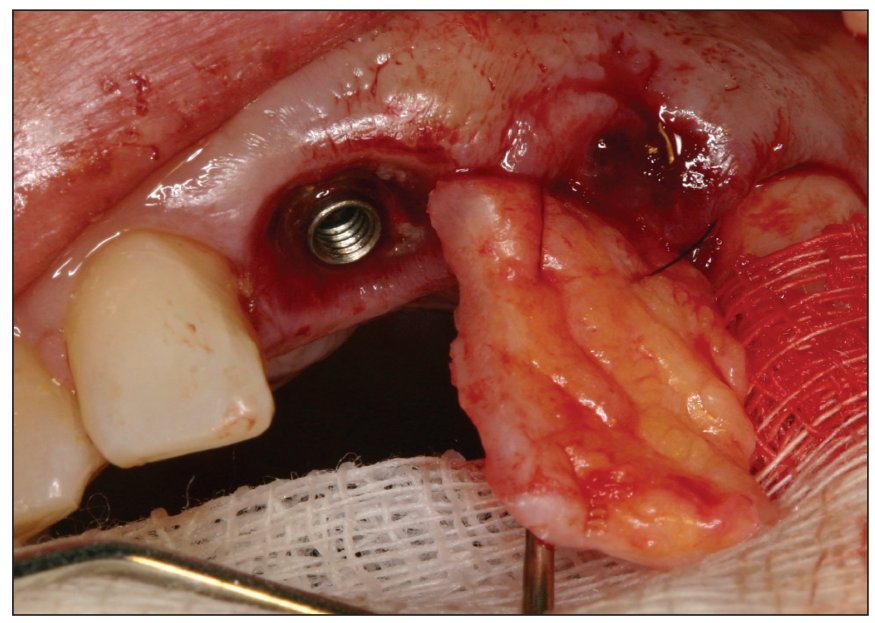

Fig.7: Inserción del tejido conectivo ayudado por la sutura.

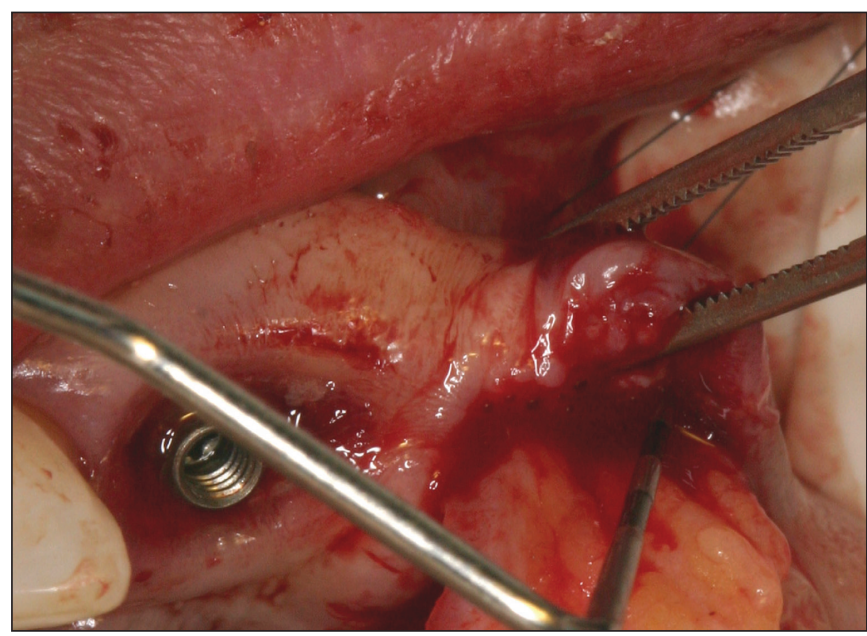

Fig.8: Inserción del injerto conectivo ayudándonos con la sonda.

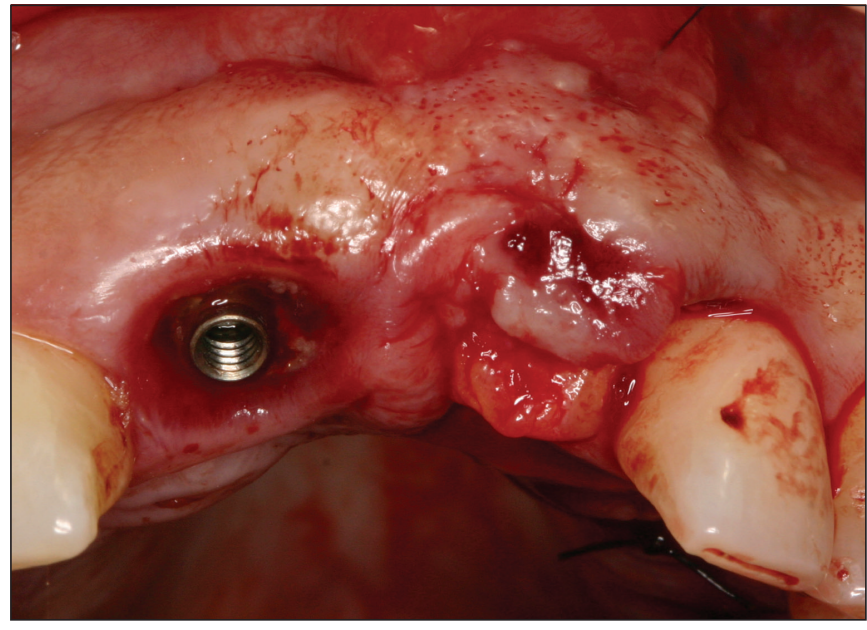

Fig.9: Inserción del injerto a la altura deseada.

al comprobar la movilidad del injerto al mover el labio, comprobamos que al mover el labio superior del paciente el injerto se desplaza; para su estabilidad realizamos suturas ancladas en los dientes contiguos al lugar de la intervención y al área lateral del área vestibular de la intervención (Figs. 11 y 12).

Una vez realizadas todas las suturas e inmovilizados el injerto, procedemos a la recolocación del puente, realizando una ligera presión sobre la zona postquirúrgica para el contorneado del margen gingival.

La adaptación del injerto libre de tejido conectivo sobre el lecho receptor en sobre se produce a lo largo de una serie de fases (12); la primera, la fase inicial, se produce desde el momento de postintervención hasta el tercer día, destacando la existencia de una

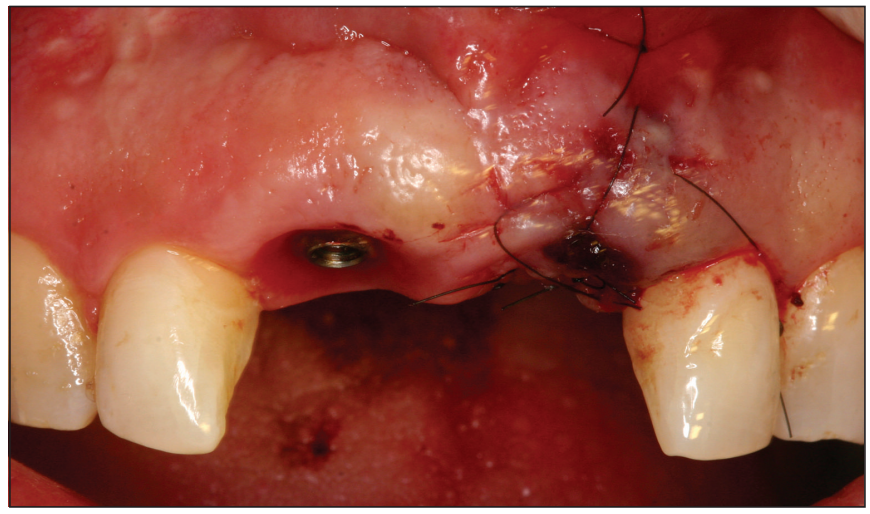

Fig. 10: Plano de la sutura desde vestibular. 


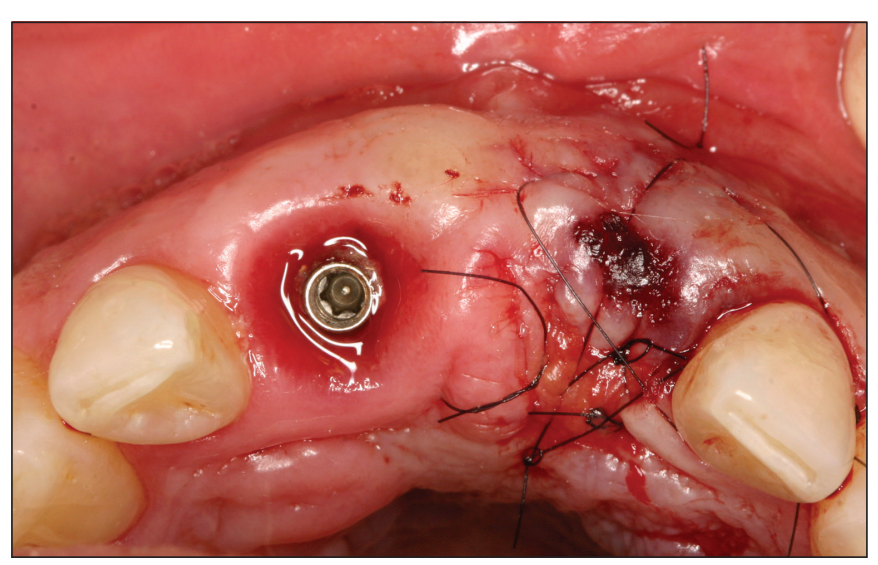

Fig.11: Sutura desde incisal.

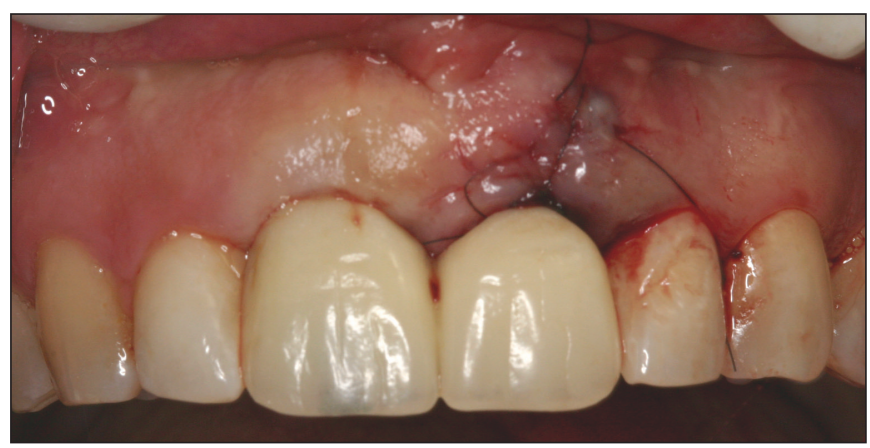

Fig.12: Colocación del puente provisional tras la intervención.

fina capa de exudado entre el injerto y el lecho receptor, durante este periodo el injerto sobrevive con una circulación plasmática avascular procedente del estrecho contacto con el lecho receptor, ya que las áreas radiculares que cubre el injerto sobre las recesiones no dan aporte vascular, pudiendo comprometer su supervivencia; el epitelio del injerto se genera al principio de esta etapa, descamándose a continuación. La segunda etapa, de revascularización, se desarrolla desde el tercer al décimo primer día (Fig. 13), desencadenando una anastomosis entre los vasos del lecho y del injerto, proliferando gradualmente la red de vasos sanguíneos en el transplante, y creando una unión fibrosa entre receptor e injerto, acompañada de una nueva reepitelización del injerto por proliferación del epitelio de los tejidos adyacentes. La última fase, de maduración del tejido, transcurre desde el décimo primer día hasta el cuarenta y dos, el sistema vascular del injerto se restablece y el epitelio madura con formación de una capa queratinizada.



Fig.13: Una semana de cicatrización.

Posteriormente, con los provisionales ovoides manejaremos el margen gingival, realizando una ligera presión modificada temporalmente (Figs. 14 y 15), e intentando que el punto más apical del margen gingival en la zona vestibular llamado "cenit gingival", se encuentre localizado en distal al eje longitudinal del diente de los incisivos centrales y en el incisivo lateral superior en el punto más central o coincidente de dicho

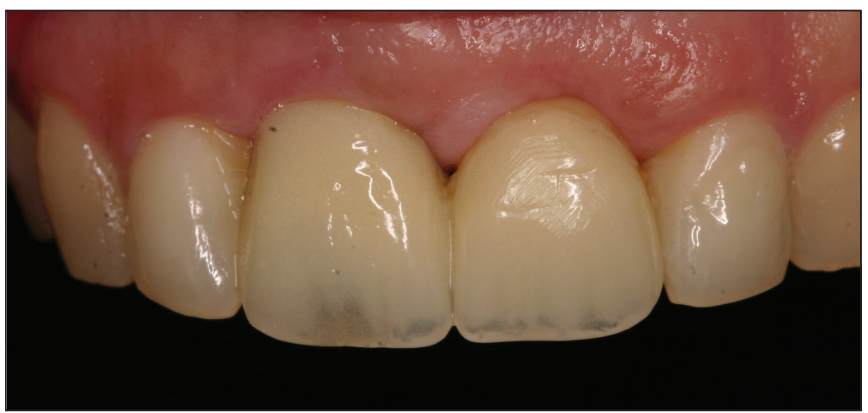

Fig. 14: Manejo de tejidos blandos con los provisionales.

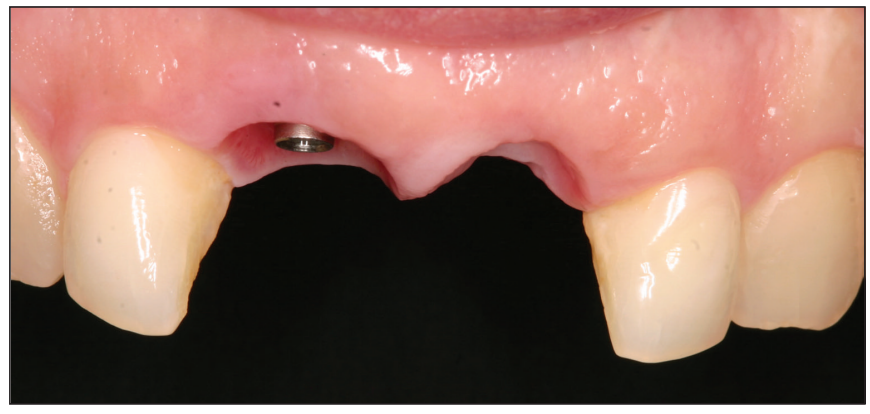

Fig. 15: Situación estética de la cresta post-tratamiento sin el póntico. 
eje (13). Con los pónticos ovoides, obtendremos una estética correcta debido a la producción de un correcto perfil de emergencia, y a la disminución y eliminación de los triángulos negros aportando aparentemente la existencia de pseudopapilas.

\section{DISCUSIÓN}

Las consecuencias del colapso de tejidos blandos son la falta de papilas, con la consecuente aparición de triángulos negros, la falta de prominencia radicular, etc. Antes de reconstruir el colapso de la cresta debemos tener una serie de factores en cuenta, como por ejemplo, la morfología del defecto $(1,2)$, tener en cuenta la cantidad y calidad de tejido blando existente en la zona edéntula para permitir la elevación de un colgajo y, por tanto, evitar la perforación de éste, tener en cuenta el aporte sanguíneo de la zona receptora, la ausencia de bolsas periodontales, la preservación de la papila marginal en dientes adyacentes, una apropiada evaluación de la cantidad y calidad del material de injerto de la zona donante y la evaluación del número de procedimientos quirúrgicos necesarios para lograr óptimos resultados (13).

Para la obtención del injerto es necesario el conocimiento anatómico de la zona, al elegir como zona donante el paladar, planificaremos su diseño (14) para evitar interferencias con la arteria palatina, teniendo en cuenta los tipos de paladar, destacando un mayor riesgo de perforación de la arteria palatina en el paladar tipo plano; calculando la distancia del LAC a la arteria palatina y destacando que el mayor espesor de tejido conectivo se sitúa a nivel de premolares.

El manejo quirúrgico de los tejidos debe ser muy minucioso para evitar el fracaso de los injertos de tejido conectivo al perforar el colgajo, o unas dimensiones de tejido conectivo inadecuadas, etc.

La técnica inlay nos aporta una serie de ventajas, tales como la ganancia de un volumen inicial moderado en una sola intervención, un bajo riesgo de necrosis, un buen pronóstico y una buena adaptación del color de la encía, factor muy importante debido a la demanda estética del frente anterior.

El manejo de tejidos blandos del sector anterior lo realizaremos a través de pónticos ovoides, aportándonos una buena estética e higiene (7), la forma de manejar los tejidos blandos en el presente artículo, se realiza a través de una ligera presión del póntico so- bre el tejido blando $(7,13)$; aunque existen otras formas de modificación del margen gingival como sería la realización de gingivectomía con una fresa de diamante (7).

La obtención de la papila la conseguiremos en función de la distancia entre el punto de contacto con el diente adyacente y la cresta ósea, la necesidad de una cierta altura para la obtención de la papila dependerá de las estructuras contiguas. Si necesitamos obtener papila entre diente e implante, la distancia del punto de contacto a la cresta deberá ser como mínimo de $4,5 \mathrm{~mm}$ (15); entre implante y póntico la distancia deberá ser menor de 5,5 mm (16); y entre diente y póntico deberá se menor de 6,5 mm (16).

\section{CONCLUSIONES}

A través del aumento de la cresta con un injerto inlay de tejido conectivo y una modificación del margen gingival a través de pónticos ovoides, se consiguen muy buenos resultados estéticos y funcionales del paciente, facilitando la higiene de la zona.

\section{ABSTRACT}

In general, the edentulous area prevents a correct relationship between pontic-ridge, and it unleashes an aesthetic absence in the anterior front cases. To achieve this kind of defects we could use different kinds of techniques to modify a type III Seibert defect (1) through a connective tissue graft and an ovate pontic.

\section{KEY WORDS}

Seibert's Classiffication, connective tissue graft, Cantilever.

\section{BIBLIOGRAFÍA}

1. Seibert JS. Reconstruction of deformed, partially edentulous ridges, using full thickness onlay grafts. Part I. Technique and wound healing. The Compendium of continuing education in dentistry. $1983 \mathrm{Sep}-\mathrm{Oct} ; 4(5)$ : 437-53.

2. Allen EP, Gainza CS, Farthing GG, Newbold DA. Improved technique for localized ridge augmentation. 
A report of 21 cases. Journal of periodontology. 1985 Apr;56(4):195-9.

3. Abrams L. Augmentation of the deformed residual edentulous ridge for fixed prosthesis. The Compendium on continuing education in general dentistry. 1980 MayJun; 1(3):205-13.

4. Miller PD, Jr. Ridge augmentation under existing fixed prosthesis. Simplified technique. Journal of periodontology. 1986 Dec;57(12):742-5.

5. Seibert JS. Ridge augmentation to enhance esthetics in fixed prosthetic treatment. Compendium (Newtown, Pa. 1991 Aug;12(8):548, 50, 52 passim.

6. Meltzer JA. Edentulous area tissue graft correction of an esthetic defect. A case report. Journal of periodontology. 1979 Jun;50(6):320-2.

7. Liu CL. Use of a modified ovate pontic in areas of ridge defects: a report of two cases. J Esthet Restor Dent. 2004; 16(5):273-81.

8. Gamer S, Tuch R, Garcia LT. M. M. House mental classification revisited: Intersection of particular patient types and particular dentist's needs. J Prosthet Dent. 2003 Mar;89(3):297-302.

9. Muhlemann HR, Son S. Gingival sulcus bleeding-a leading symptom in initial gingivitis. Helvetica odontologica acta. 1971 Oct;15(2):107-13.

10. Escudero-Castaño N L-VR, Bascones-Martínez A. Cirugía plástica periodontal de múltiples recesiones con la técnica de túnel modificada. Un caso clínico. JADA. 2007;2(2):421-6.
11. Sullivan HC, Atkins JH. Free autogenous gingival grafts. I. Principles of successful grafting. Periodontics. 1968 Jun;6(3):121-9.

12. Oliver RC, Loe H, Karring T. Microscopic evaluation of the healing and revascularization of free gingival grafts. Journal of periodontal research. 1968;3(2):84-95.

13. Aguilera Esparza G RGF. Estética dentogingival en prótesis fija con póntico ovoide Revista de la Asociación Dental Mexicana. 2004;61(5).

14. Reiser GM, Bruno JF, Mahan PE, Larkin LH. The subepithelial connective tissue graft palatal donor site: anatomic considerations for surgeons. The International journal of periodontics \& restorative dentistry. 1996 Apr; 16(2):130-7.

15. Salama H, Salama MA, Garber D, Adar P. The interproximal height of bone: a guidepost to predictable aesthetic strategies and soft tissue contours in anterior tooth replacement. Pract Periodontics Aesthet Dent. 1998 NovDec;10(9):1131-41; quiz 42.

16. Salama H, Salama, M., Garber, D. \& Adar, P. The interproximal height of bone: a guidepost to esthetic strategies and soft tissue contours in anterior tooth replacement. Submitted to The Journal of Practical Periodontics and Aesthetic Dentistry Anthology edition, adapted from the wwwgoldsteingarber.com. 2004.

\section{CORRESPONDENCIA}

Nayra Escudero-Castaño.

Correo.electrónico: nayramadrid@hotmail.com 